07

\title{
Наносекундная динамика разрушения гетерогенных природных тел при трении
}

\author{
() В.И. Веттегрень ${ }^{1}$, А.В. Пономарев ${ }^{2}$, K. Arora $^{3}$, Haris Raza ${ }^{3}$, Р.И. Мамалимов ${ }^{1}$, \\ И.П. Щербаков ${ }^{1}$, И.В. Фокин ${ }^{2}$ \\ ${ }^{1}$ Физико-технический институт им. А.Ф. Иоффре РАН, \\ Санкт-Петербург, Россия \\ ${ }^{2}$ Институт фиизики Земли им. О.Ю. Шмидта РАН, \\ Москва, Россия \\ ${ }^{3}$ CSIR National Geophysical Research Institute, \\ Hyderabad, India \\ E-mail: Victor.Vettegren@mail.ioffe.ru
}

(Поступила в Редакцию 5 марта 2017 г.

В окончательной редакции 12 апреля 2018 г.)

Получены спектры и исследована динамика интенсивности люминесценции, возникающей при трении гетерогенных тел (базальта и гранита). При трении кристаллические решетки этих тел, разрушаются и образуются люминесцирующие свободные радикалы $\equiv \mathrm{Si}-\mathrm{O}^{-}$, ионы $\mathrm{Fe}^{3+}$ и ловушки электронов, расположенные на поверхности микротрещин. С временным разрешением $2 \mathrm{~ns}$ исследована динамика накопления микротрещин и определены их размеры $-\sim 6-10 \mu \mathrm{m}$.

Работа выполнена при частичной финансовой поддержке Российского фонда фундаментальных исследований, грант № 16-05-00137 (получение и анализ спектров образцов до и после трения) и Российско-индийского проекта РНФ-DST India: грант Российского научного фонда № 16-47-02003, грант Департамента науки и технологии Правительства Индии - INT/RUS/RSF/P-13.13 (отбор и изготовление образцов, их петрографический анализ).

DOI: 10.21883/FTT.2018.11.46674.057

\section{1. Введение}

Известно, что трение твердых тел неустойчиво. Неустойчивость перемещения блоков горных пород, по-видимому, является основной причиной землетрясений [1-5]. Экспериментальные исследования строения поверхностей горных пород, образовавшихся при скольжении, были начаты в работах [6-9]. Используя методы инфракрасной, рамановской и фотолюминесцентной (PL) спектроскопии, авторы установили, что при скольжении на поверхности горных пород образуются тонкие слои глин, насыщенных водой и имеющих низкий коэффициент трения. Образование таких слоев может быть причиной упомянутой неустойчивости скольжения блоков горных пород.

Было предположено, что механическое напряжение при трении приводит к разрушению ячеек кристаллических решеток минералов, входящих в состав горных пород. При разрушении образуются свободные радикалы. Они вызывают химические реакции, которые и приводят к образованию глин. Свободные радикалы действительно были обнаружены при анализе спектров триболюминесценции (TL), полученных во время трения горных пород [10-15].

Настоящая работа продолжает цикл этих исследований. Ее цель - исследование свободных радикалов, образующихся в кристаллических решетках плагиоклаза и кварца при трении базальта и гранита.

\section{2. Объекты и методы исследования}

Образцы изготовлены из горных пород, добытых из скважины в зоне триггерной сейсмичности в районе Койна-Варна, Индия. Первая порода, базальт, была извлечена с глубины $314 \mathrm{~m}$, а вторая, (гранит) с глубины $689 \mathrm{~m}$.

Базальт содержал кристаллы плагиоклаза $\sim 40 \%$ vol., клинопироксена — $\sim 40 \%$ vol. и рудного минерала - 15-20\% vol. Кристаллы плагиоклаза представляли собой лейсты длиной до $100 \mu \mathrm{m}$. Клинопироксен заполнял участки между кристаллами плагиоклаза.

Гранит содержал искаженные кристаллы плагиоклаза $(40 \%$ vol.), кварца $(20-25 \%$ vol.) и др. минералов (хлорита - 15\% vol., роговой обманки - 10\% vol., эпидота и апатита $-\sim 15 \%$ vol.).

Для исследования TL была создана установка, состоящая из вращающегося диска, одетого на ось электромотора (частота оборотов - $47.5 \mathrm{~s}^{-1}$ ), и прижатого к нему стержня. Диск и стержень были вырезаны из образцов исследуемых пород (описание установки приведено в [10]).

Диски готовили следующим образом. Из керна вырубали кольца толщиной $\sim 15 \mathrm{~mm}$. Внутренняя полость колец была заполнена кварцевым песком, смешанным с эпоксидной смолой (рис. 1). В центре образца сделано отверстие для посадки на ось электромотора. Диаметр диска из базальта $-63 \mathrm{~mm}$, а из гранита $-47 \mathrm{~mm}$. 


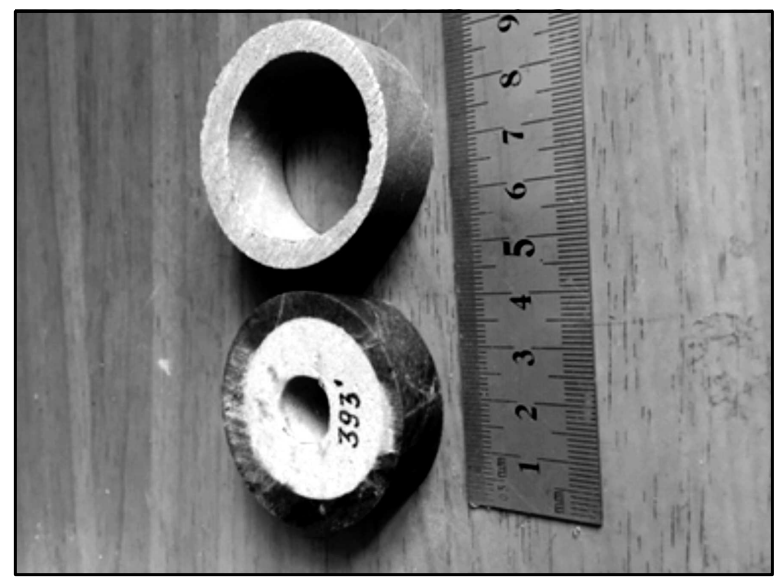

Рис. 1. Фотография диска из гранита. Наверху - кольцо из гранита. Внизу - это же кольцо, заполненное отвердевшей эпоксидной смолой, наполненной кварцевым песком. Отверстие в центре - для посадки на ось электромотора.

Стержни из базальта и гранита имели длину $45 \mathrm{~mm}$ и диаметр - $9.5 \mathrm{~mm}$. Концы стержней затачивались на точильном круге. Диаметр плоского конца заточенных стержней - $2 \mathrm{~mm}$. Трение вызывало TL, спектры регистрировали оптоволоконным спектрометром AvaSpec-ULSi2048L-USB2 OE.

Чтобы исследовать динамику TL, излучение кварцевым световодом подавалось на поверхность фотоэлектронного умножителя РМТ 136, а с него - на вход аналоговоцифрового преобразователя ADS-3112. Сигнал с выхода ADS с временным разрешением 2 ns записывался в память компьютера для дальнейшей обработки и хранения.

Спектры PL до и после трения возбуждали светодиодом UVTOP280TO39HS (длина волны излучения - $285 \mathrm{~nm}$ ) и записывали на спектрометре AvaSpec-ULSi2048L-USB2 OE. Измерения проводились в пяти разных местах, полученные данные усредняли.

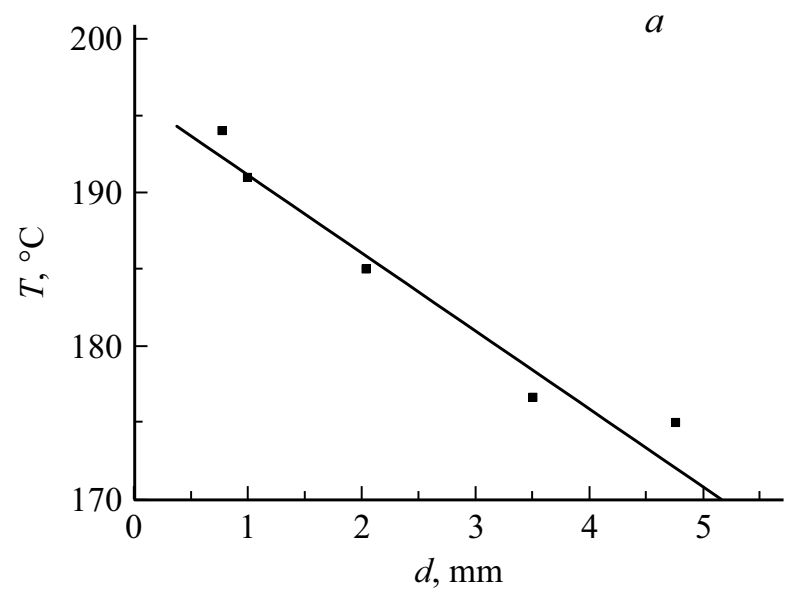

На величину интенсивности полос в спектре PL влияет рассеяние на шероховатой поверхности образца. Чтобы уменьшить искажения, вызванные рассеянием их влияние на результаты измерений, мощность излучения лазера подбиралась такой, чтобы величина интенсивности света, отраженного от поверхности, была одинаковой.

\section{3. Определение температуры в зоне трения}

При трении диск и стержень нагреваются. Чтобы оценить температуру в зоне трения, вдоль оси стержней был пропилен паз глубиной $\sim 1 \mathrm{~mm}$ и в него вставлена термопара. Перемещая термопару внутри паза, измеряли температуру стержня $T(x)$ на различных расстояниях $x$ от зоны трения. В стационарных условиях температура $T(x)$, связана с температурой $T(0)$ в зоне трения выражением (уравнение Пуассона) [16]:

$$
T(x)=T(0)-\frac{F(x)}{\lambda} x,
$$

где $F(x)$ - плотность теплового источника, а $\lambda-$ коэффициент теплопроводности.

В соответствии с этим уравнением, зависимость температуры от расстояния оказалась линейной (рис. 2). Экстраполируя прямые линии к $x=0$, оценили $T(0)$ базальта $-\sim 200^{\circ} \mathrm{C}$ и гранита $-\sim 180^{\circ} \mathrm{C}$.

\section{4. Спектры люминесценции}

Спектры TL показаны на рис. 3. Они состоят из нескольких, наложенных друг на друга полос, которые имеют гауссову форму [17]. После разложения определили энергию максимумов и интенсивности этих полос.

Полоса $1.93 \mathrm{eV}$ приписана возбужденным свободным радикалам $\equiv \mathrm{Si}-\mathrm{O}^{-}[18]$. Эти радикалы образуются при разрывах химических связей $\mathrm{Si}-\mathrm{O}-\mathrm{Si}$ в кристаллической решетке кварца.

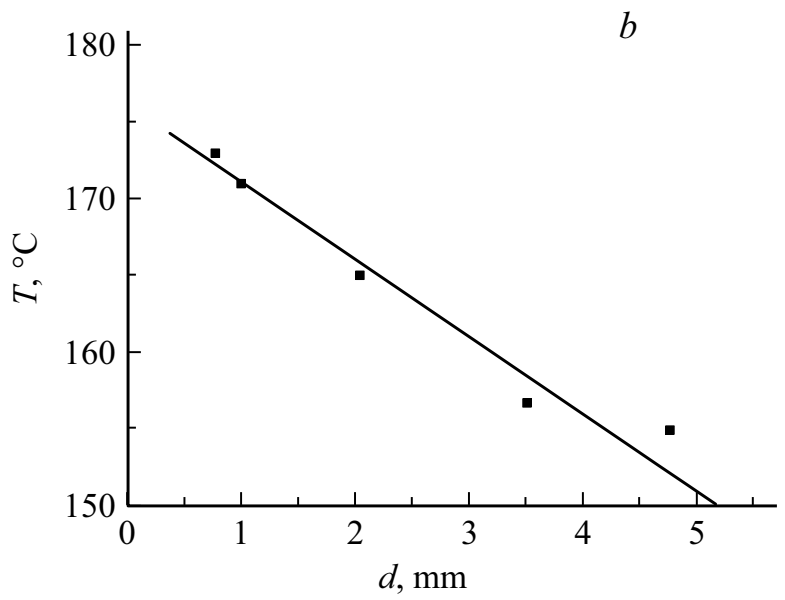

Pис. 2. Зависимость температуры стержня от расстояния до зоны трения: $a-$ базальт; $b-$ гранит. 

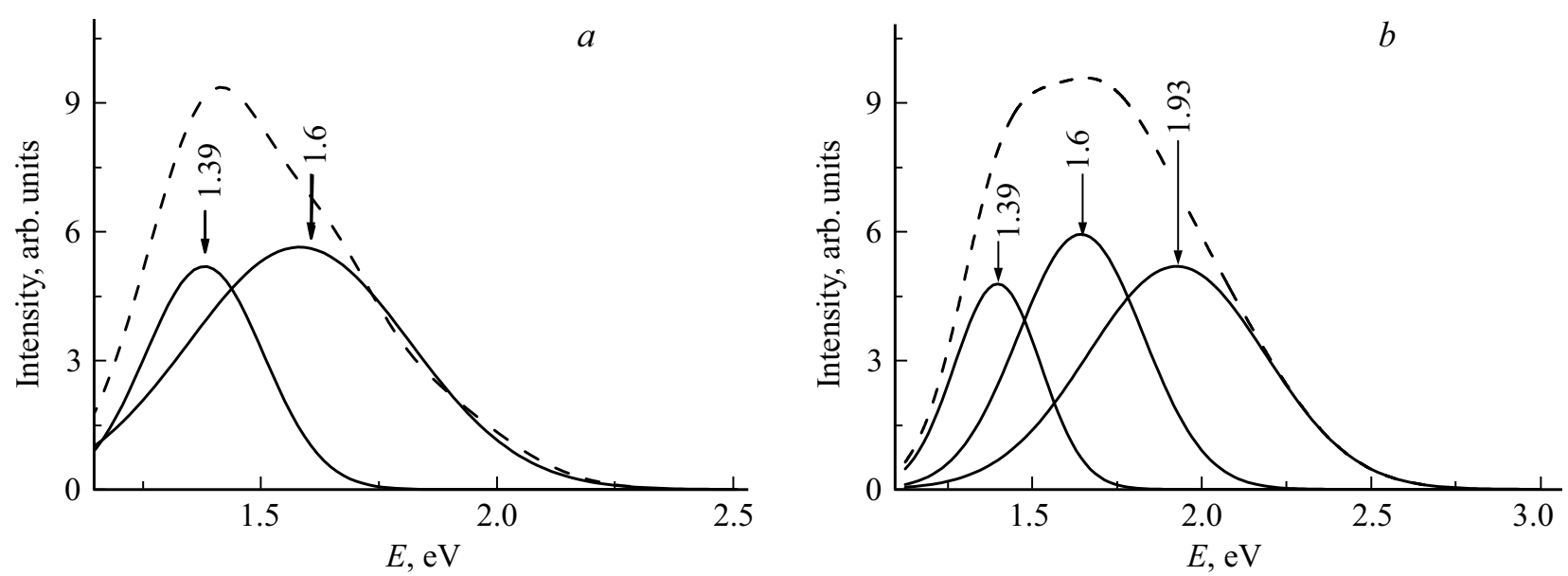

Рис. 3. Спектры люминесценции при трении базальта $(a)$ и гранита $(b)$ (пунктир) и их разложение на составные полосы (сплошные линии).

Максимум $\quad 1.6 \mathrm{eV}$ соответствует возбужденным ионам $\mathrm{Fe}^{3+}$, замещающих ионы $\mathrm{Si}^{4+}$ в кристаллических ячейках плагиоклаза и кварца [18].

Природа полосы $1.39 \mathrm{eV}$ требует более детального обсуждения. Авторы работ [19-22] наблюдали в спектре оптически стимулированной люминесценции (OSL) плагиоклаза появление полосы $1.44 \mathrm{eV}$, которую приписали переходу электронов из акцепторных ловушек в зону проводимости. При обратном переходе электрон из зоны проводимости сначала переходит на промежуточный уровень, а затем в пустую ловушку. В результате выделяется энергия в диапазоне от 1.36 до $1.39 \mathrm{eV}$ [20-23].

Явление OSL было положено в основу широко применяемого в настоящее время метода датирования полевых шпатов [21,24]. Известно, что полевые шпаты содержат радиоактивные элементы, при распаде которых возникает ионизирующее излучение. Оно создает радиационные повреждения - акцепторные ловушки. С течением времени - от момента образования, до момента добычи полевые шпаты накапливают ловушки. После добычи образец полевого шпата облучают светом и рассчитывают возраст породы как величину отношения выделенной энергии к поглощенной дозе радиации [24].

Наблюдение полосы $1.39 \mathrm{eV}$ в спектрах люминесценции, вызванной трением образцов базальта и гранита, показывает, что акцепторные ловушки могут появляться не только под влиянием ионизирующего излучения, но и при механическом разрушении полевых шпатов.

Свободные радикалы также можно обнаружить, если проанализировать изменения в спектрах PL после трения. Изменения в спектре PL базальта твердо зафиксировать не удалось из-за их низкой интенсивности. Наиболее убедительные результаты были получены этим методом при исследовании спектров PL гранита (рис. 4). Оказалось, что после трения увеличивается интенсивность полос $2.45,2.86$ и $3.3 \mathrm{eV}$. Полоса $2.45 \mathrm{eV}$ соответствует дефекту $\equiv \mathrm{Si}-\mathrm{O}^{-}$, захватившему ион $\mathrm{Li}^{+}$, $\mathrm{Na}^{+}$или $\mathrm{H}^{+}[18]$, полоса $2.86 \mathrm{eV}$ - самозахваченно-

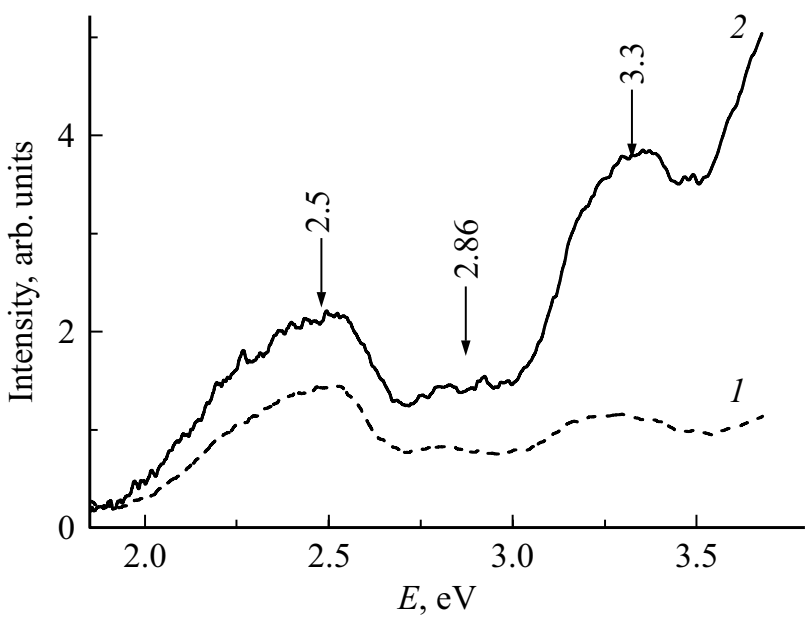

Pис. 4. Спектры PL гранита до и после трения.

му экситону [18], а $3.3 \mathrm{eV}$ - электронным ловушкам в плагиоклазе [20-23]. Самозахваченный экситон, как известно $[25,26]$, содержит свободный радикал $\equiv \mathrm{Si}-\mathrm{O}^{-}$. Анализ полученного спектра PL показывает, что при трении в кварце и плагиоклазе образуются свободные радикалы $\equiv \mathrm{Si}-\mathrm{O}^{-}$.

\section{5. Динамика триболюминесценции базальта и гранита}

Фрагменты временных зависимостей интенсивности TL базальта и гранита показаны на рис. 5. Они представляют собой набор множества $\left(\sim 10^{5}\right)$ одиночных вспышек, интенсивность которых изменяется, по крайней мере, на порядок, а время между ними варьирует от $\sim 1$ до $\sim 50 \mu \mathrm{s}$. Каждая вспышка возникает при разрушении кристаллических решеток плагиоклаза и кварца, которое вызывает образование микротрещин [10-15]. 

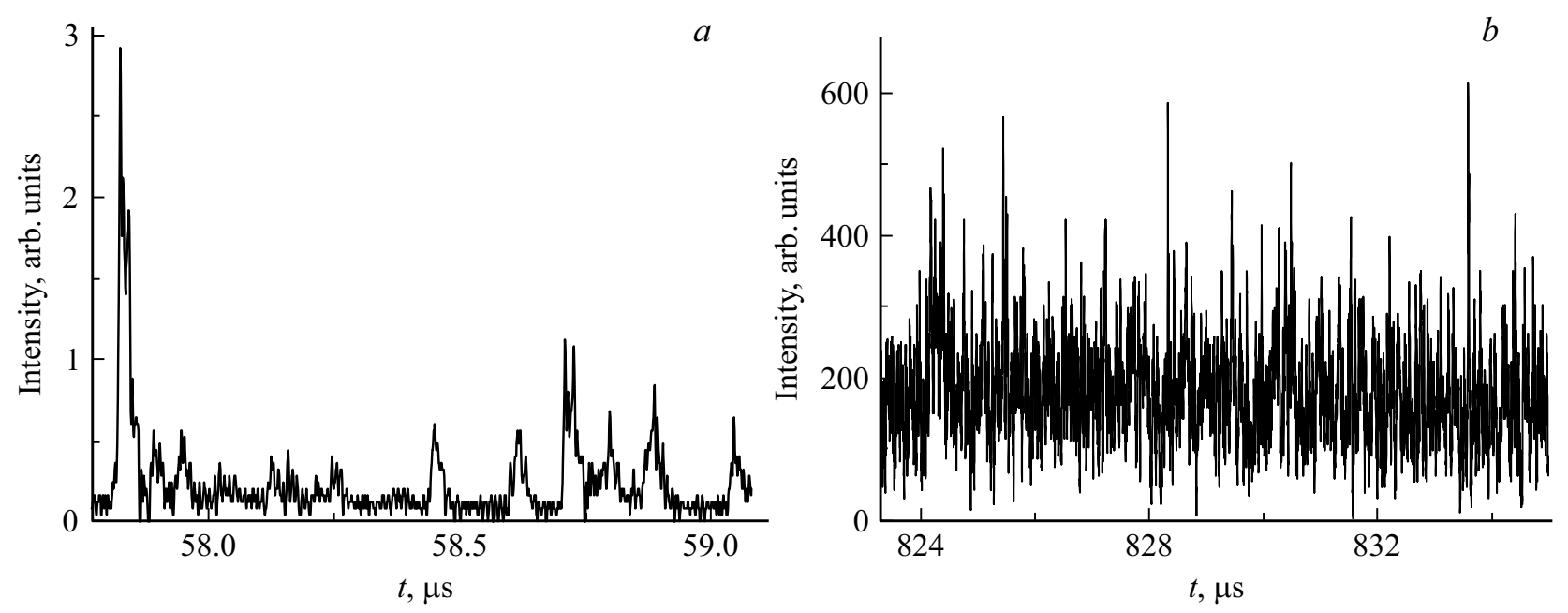

Рис. 5. Фрагменты временных зависимостей интенсивности TL базальта $(a)$ и гранита $(b)$.
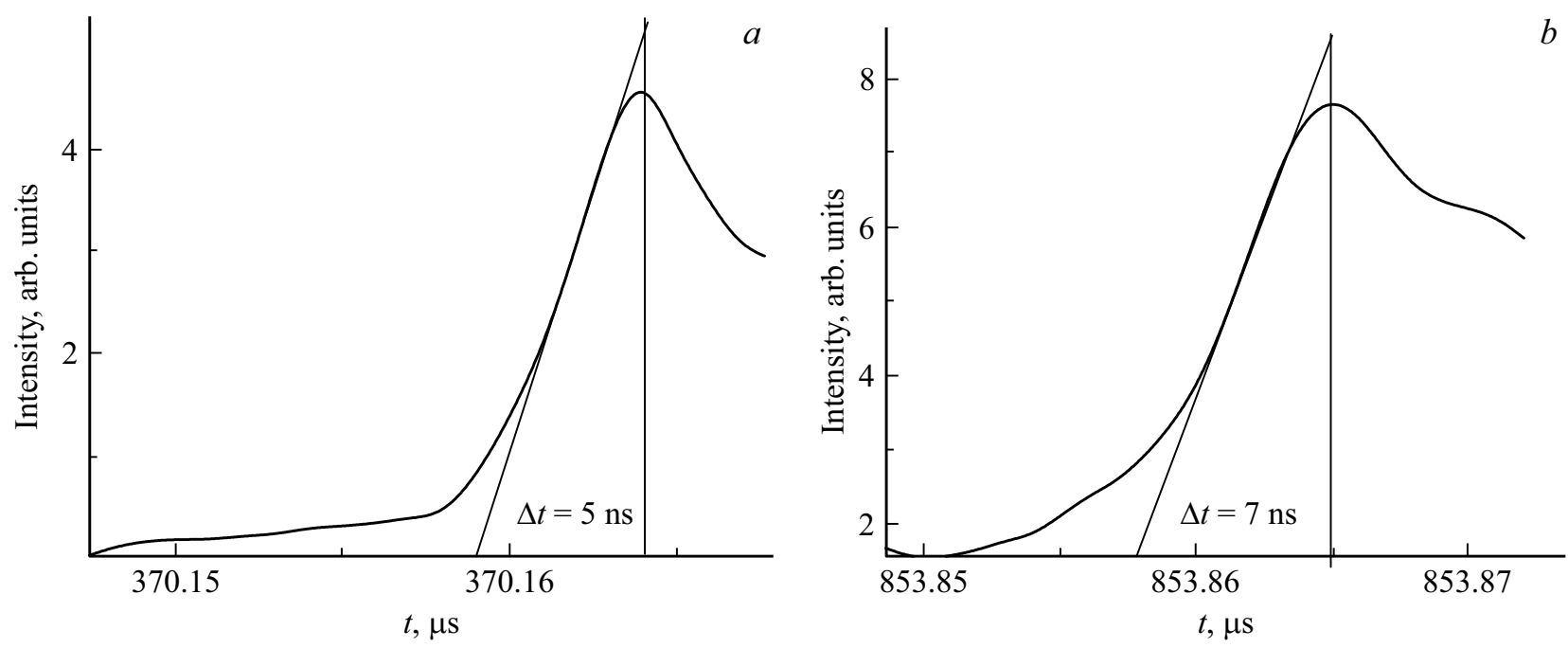

Рис. 6. „Одиночные“ вспышки TL базальта $(a)$ и гранита $(b)$.

Вспышки, как правило, наложены друг на друга. Однако при внимательном рассмотрении удается найти „одиночные“ вспышки (рис. 6). Их форма определяется скоростями двух процессов. Первый - рост интенсивности люминесценции из-за увеличения скорости роста микротрещины, а второй - ее уменьшение при замедлении и остановке микротрещин. Скорость второго процесса определяется особенностями конструкции РМТ и величинами паразитной емкости и сопротивления нагрузки. Вначале, когда скорость роста микротрещин увеличивается, скоростью последнего процесса можно пренебречь. Воспользуемся этим, и проведем касательную к интенсивности как показано на рис. 6. Продолжим ее до пересечений с вертикальной прямой, проведенной через точку с максимальной интенсивностью $I_{m}$. Тогда отрезок $\Delta t$ на оси времени будет приблизительно равен времени роста интенсивности вспышки.

Известно [27], что максимальная скорость роста трещин $v_{\text {cr }}$ приблизительно равна $1 / 3 S_{t}$, где $S_{t}-$ ско-

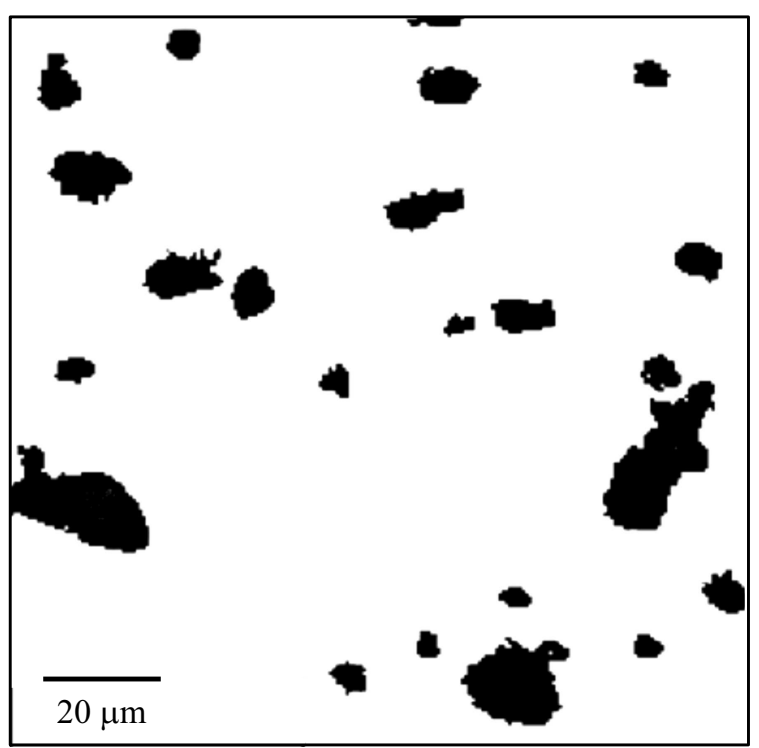

Рис. 7. Фотография частиц порошка, образовавшегося при трении гранита. 
рость поперечной звуковой волны. В полевых шпатах $S_{t} \approx 3.1-3.2 \mathrm{~km} / \mathrm{s}[28]$, т.е. $v_{\mathrm{cr}} \approx 1 \mathrm{~km} / \mathrm{s}$. Умножив это значение на время $\Delta t$ роста интенсивности наиболее интенсивных вспышек, получим приблизительный размер трещины. Оказалось, что для всех исследованных образцов базальта и гранита он составляет $\sim 6-10 \mu \mathrm{m}$.

При трении образцов базальта и гранита образовывался порошок, „зерна“ которого имели размеры от $\sim 3$ до $-20 \mu \mathrm{m}$ (рис. 7), что близко к размерам микротрещин. По-видимому, образование микротрещин приводит к откалыванию „зерен“ порошка.

\section{6. Заключение}

При трении базальта и гранита образуются микротрещины, размеры которых составляют 6-10 $\mu \mathrm{m}$. Их поверхности содержат свободные радикалы $\equiv \mathrm{Si}-\mathrm{O}^{-}$, ионы $\mathrm{Fe}^{3+}$ и ловушки электронов.

\section{Список литературы}

[1] J.D. Byerlee. Friction of rocks. Pageoph. 116, 615 (1978).

[2] J.H. Dieterich. J. Geophys. Res. B 83, 8, 3940 (1978).

[3] C.H. Scholz. Nature 391, 37 (1998).

[4] Г.А. Соболев, А.В. Пономарев. Физика землетрясений и предвестники. Наука, М. (2003).

[5] Г.А. Соболев Сейсмический шум. Наука и образование, М. (2014).

[6] Г.А. Соболев, С.М. Киреенкова, Ю.А. Морозов, А.И. Смульская, В.И. Веттегрень, В.Б. Кулик, Р.И. Мамалимов. Физика Земли 9-10, 17 (2012).

[7] Г.А. Соболев, В.И. Веттегрень, В.В. Ружич, Л.А. Иванова, Р.И. Мамалимов, И.П. Щербаков. Вулканология и сейсмология 3, 3 (2015).

[8] Г.А. Соболев, В.И. Веттегрень, В.В. Ружич, С.М. Киреенкова, А.И. Смульская, Р.И. Мамалимов, В.Б. Кулик. Геофиз. исслед. 17, 4, 5 (2015).

[9] Г.А. Соболев, В.И. Веттегрень, С.М. Киреенкова, В.Б. Кулик, Р.И. Мамалимов, Ю.А. Морозов, А.И. Смульская, И.П. Щербаков. Нанокристаллы в горных породах. ГЕОС, M. (2016).

[10] В.И. Веттегрень, А.В. Пономарев, Г.А. Соболев, И.П. Щербаков, Р.И. Мамалимов, В.Б. Кулик, А.В. Патонин. ФТТ 59, 569 (2017).

[11] В.И. Веттегрень, А.В. Пономарев, К. Arora, Р.И. Мамалимов, И.П. Щербаков, А.В. Патонин. ФТТ 59, 1319 (2017).

[12] В.И. Веттегрень, А.В. Пономарев, Г.А. Соболев, В.Б. Кулик, Р.И. Мамалимов, И.П. Щербаков, А.Я. Башкарев. ФТТ 60, 127 (2018).

[13] В.И. Веттегрень, Г.А. Соболев, А.В. Пономарев, И.П. Щербаков, Р.И. Мамалимов. ФТТ 59, 931 (2017).

[14] В.И. Веттегрень, А.В. Пономарев, И.П. Щербаков, Р.И. Мамалимов. ФТТ 59, 1557 (2017).

[15] В.И. Веттегрень, А.В. Пономарев, И.П. Щербаков, Р.И. Мамалимов. ФТТ 59, 2263 (2017).

[16] R.B. Bird, W.E. Stewart, E.N. Lightfoot. Transport Phenomena. J. Wiley \& Sons, N. Y. (2007). 905 p.

[17] N.J. Turro. Modern Molecular Photochemistry. Columbia University, University Sci. Press. (1991). 628 p.
[18] J. Götze. Microsc. Microanal. 18, 1270 (2012).

[19] T. Trautmann, M.R. Krbetschek, A. Dietrich, W. Stolz. J. Luminescence 85, 45 (1999).

[20] M.R. Baril, D.J. Huntley. J. Phys.: Condens. Matter. 15, 8011 (2003).

[21] D.J. Huntley, D.I. Godfrey-Smith, M.L.W. Thewalt. Nature 313, 105 (1985).

[22] D.J. Huntley, M.R. Baril, S. Haidar. J. Phys. D 40, 900 (2007).

[23] M.R. Krbetschek, U. Rieser. Rad. Measurements. 24, 473 (1995).

[24] G.A. Wagner. Age Determination of Young Rocks and Artifacts. Springer-Verlag, Berlin Heidelberg (1998).

[25] R.T. Williams, K.S. Song. J. Phys. Chem. Solids 51, 7, 679 (1990).

[26] A.J. Fisher, W. Hayest, A.M. Stonehams. J. Phys.: Condens. Matter 2, 6707 (1990).

[27] В.Р. Регель, А.И. Слуцкер, Э.Е. Томашевский. Кинетическая природа прочности твердых тел. Наука, М. (1974).

[28] J.H. Schön. Physical Properties of Rocks. A workbook. Elsevier, Amsterdam (2011).

Редактор Д.В. Жуманов 